\title{
REMOÇÃO DA ADSTRINGÊNCIA DE FRUTOS DE CAQUIZEIRO 'GIOMBO' SOB DIFERENTES PERÍODOS DE EXPOSIÇÃO AO VAPOR DE ÁLCOOL ETÍLICO'
}

\author{
LUCIMARA ROGÉRIA ANTONIOLLI², PAULO ROBERTO DE CAMARGO E CASTRO³, \\ RICARDO ALFREDO KLUGE ${ }^{4}$ e JOÃO ALEXIO SCARPARE FILHO ${ }^{5}$
}

\begin{abstract}
RESUMO - O objetivo deste trabalho foi avaliar o efeito do período de exposição ao vapor de álcool etílico na remoção da adstringência de frutos de caquizeiro (Diospyros kaki L.) cultivar Giombo. Os frutos foram expostos ao vapor de álcool durante 24,36 e 48 horas, sob temperatura de $20^{\circ} \mathrm{C}$ e $95 \%$ de umidade relativa. As características químicas e físicas dos frutos foram avaliadas durante dez dias, em intervalos de dois dias. As variáveis analisadas foram: teor de taninos solúveis, firmeza da polpa, perda de matéria fresca, $\mathrm{pH}$, sólidos solúveis totais, acidez total titulável e teor de ácido ascórbico. De acordo com os resultados obtidos, os períodos de 24 e 36 horas demonstraram ser igualmente eficientes no processo de remoção da adstringência dos frutos; no entanto, a avaliação das demais características indicou melhor qualidade dos frutos expostos durante o período de 24 horas. Constatou-se uma diminuição linear na firmeza da polpa em função do tempo. O melhor período para consumo dos frutos situou-se entre o 4o e o 8o dia após o tratamento, considerando-se que a partir do $4^{\circ}$ dia a concentração de taninos solúveis ficou abaixo de $0,1 \%$, imperceptível ao paladar, e a firmeza da polpa dos frutos se manteve aceitável durante o período de oito dias posteriores ao tratamento.
\end{abstract}

Termos para indexação: Diospyros kaki, fisiologia pós-colheita, produção de etileno, tanino, amadurecimento.

\section{ASTRINGENCY REMOVAL OF 'GIOMBO' PERSIMMON FRUIT IN DIFFERENT EXPOSURE PERIODS TO ETHYL ALCOHOL VAPOR}

\begin{abstract}
The purpose of this research was to study the effect of exposure period to ethyl alcohol vapor on astringency removal of persimmon fruits (Diospyros kaki L.) cv. Giombo. Fruits were exposed to alcohol vapor for 24,36 and 48 hours at $20^{\circ} \mathrm{C}$ and $95 \% \mathrm{RH}$. Chemical and physical characteristics of fruits were measured for ten days, at two day intervals. Soluble tannin content, flesh firmness, water loss, $\mathrm{pH}$, soluble solids, titratable acidity and ascorbic acid content were measured. This research showed that 24 and 36 hours were equally efficient in the astringency removal of fruits, although the analysis of other quality indices showed that fruits exposed for 24 hours exhibited better quality. The flesh firmness underwent a linear decrease in terms of time. The best period for consumption of the fruits was placed between the $4^{\text {th }}$ and $8^{\text {th }}$ day after the treatment. Fruits became edible at the $4^{\text {th }}$ day after the treatment, when the content of soluble tannins was under $0.1 \%$, imperceptible to taste, and the flesh firmness was kept for 8 days after the treatment.
\end{abstract}

Index terms: Diospyros kaki, postharvest physiology, ethylene production, tannins, ripening.

${ }^{1}$ Aceito para publicação em 13 de janeiro de 2000.

Parte da dissertação de mestrado apresentada pelo primeiro autor à Escola Superior de Agricultura Luiz de Queiroz (ESALQ).

${ }^{2}$ Eng. Agrôn., M.Sc., Dep. de Pré-Processamento de Produtos Agropecuários, Faculdade de Engenharia Agrícola (FEAGRI), Universidade Estadual de Campinas (UNICAMP), Caixa Postal 6011, CEP 13083-970 Campinas, SP. E-mail: 1rantoni@agr.unicamp.br

${ }^{3}$ Eng. Agrôn., Dr., Prof. Titular, Dep. de Ciências Biológicas, ESALQ. E-mail: prccastr@ carpa.ciagri.usp.br

${ }^{4}$ Eng. Agrôn., Dr., Dep. de Ciências Biológicas, ESALQ. E-mail: rakluge@ carpa.usp.br

${ }^{5}$ Eng. Agrôn., Dr., Dep. de Produção Vegetal, ESALQ.

E-mail: jascarpa@carpa.ciagri.usp.br

\section{INTRODUÇÃO}

As cultivares de caquizeiro (Diospyros kaki L.), de origem japonesa, podem ser divididas em dois tipos distintos, a saber: aquelas cujos frutos não apresentam mudança na coloração da polpa em função da polinização (constantes em relação à polinização - PC) e aquelas cujos frutos apresentam polpa clara, quando partenocárpicos, e escura, quando fecundados (variáveis em relação à polinização - PV). Os frutos podem ser, ainda, subdivididos em adstringentes (A) e não-adstringentes (NA) (Ito, 1971). Dessa forma, as cultivares de 
caquizeiro podem ser classificadas entre os tipos básicos: PCA, PCNA e PV, sendo que os frutos das cultivares de polinização variável podem ser adstringentes ou não-adstringentes.

Dependendo do teor de tanino e da presença ou não de coloração "chocolate" na polpa, próximo às sementes, os frutos são classificados, nas condições brasileiras, entre os três diferentes tipos básicos: taninoso ("sibugaki"), variável ("variant sibugaki" ou "variant amagaki") e doce ("amagaki"), conforme Campo-Dall'Orto et al. (1996).

A cultivar Giombo é classificada por Ito (1971), como pertencente ao tipo PCA; no entanto, Martins \& Pereira (1989) citam a cultivar como pertencente ao tipo variável, apresentando frutos com polpa bastante taninosa quando partenocárpicos, e do tipo "chocolate" e, portanto, sem adstringência, quando com numerosas sementes. Nos frutos com poucas sementes, a coloração escura é verificada somente ao redor das sementes (Martins \& Pereira, 1989).

Uma vez que são, na sua maioria, consumidos in natura, os frutos das cultivares adstringentes requerem remoção artificial da adstringência anterior ao consumo. São vários os produtos que podem ser utilizados na remoção da adstringência do caqui: álcool, vinagre, água de cal, etileno, ethephon e carbureto de cálcio (Penteado, 1986; Biasi \& Gerhardt, 1992). Tais tratamentos estimulam o acúmulo de compostos voláteis na polpa dos frutos, como etanol e acetaldeído, e estas substâncias, especialmente o acetaldeído, induzem os taninos solúveis a se polimerizarem e formarem complexos insolúveis, resultando, com isso, na perda da adstringência (Sugiura \& Tomana, 1983). Taninos altamente condensados são menos solúveis e apresentam menor capacidade de se ligar a outros componentes celulares (Buren, 1970).

Costa (1984), avaliando o comportamento de algumas cultivares de caquizeiro, afirmou que os frutos de 'Giombo' destacaram-se entre os melhores para o consumo in natura, após serem submetidos, durante um período de 60 horas, ao tratamento com acetileno, proveniente de carbureto de cálcio à proporção de $100 \mathrm{~g} \mathrm{~m}^{-3}$, realizado em câmara de amadurecimento.
Os frutos de caquizeiro 'Okira' tratados com álcool apresentaram, após o processo de destanização, resistência da polpa superior à dos frutos tratados com vinagre e ethephon (Biasi \& Gerhardt, 1992). Este resultado confirmou as observações de Martins \& Pereira (1989), que citaram o álcool como um agente destanizador que possibilitou a obtenção de frutos com polpa firme após o processo. Pesis et al. (1986) associaram o início do amolecimento da polpa de frutos de caquizeiro 'Triumph' ao valor de firmeza de $4,2 \mathrm{~kg} \mathrm{~cm}^{-2}$.

Conforme observações de Fukushima et al. (1991), o tratamento com etanol proporcionou maior rapidez no processo de perda da adstringência em caquis 'Hiratanenashi', em comparação com o tratamento com acetaldeído. Quando realizado sob temperaturas de $15^{\circ} \mathrm{C}$ ou $20^{\circ} \mathrm{C}$, tal tratamento possibilitou a manutenção da qualidade dos frutos por um período igual ou superior a dez dias (Kato, 1987).

O objetivo deste trabalho foi avaliar o efeito do período da exposição ao vapor de álcool etílico na remoção da adstringência de frutos de caquizeiro, cultivar Giombo, avaliando-se as alterações físicoquímicas dos frutos após o processo de destanização e a manutenção de qualidade para consumo.

\section{MATERIAL E MÉTODOS}

Os frutos de caquizeiro 'Giombo' foram colhidos no início do mês de junho de 1998, em pomar comercial localizado no município de Guapiara, SP, situado a $24^{\circ} 11^{\prime}$ de latitude Sul e $48^{\circ} 2^{\prime}$ de longitude Oeste e a 900 metros de altitude, com clima do tipo $\mathrm{Cfb}$, segundo Köppen.

Em razão da colheita tardia, considerando-se que o período de colheita desta cultivar, inicia-se no mês de março e estende-se até fins de maio (Martins \& Pereira, 1989), os frutos apresentavam coloração $100 \%$ alaranjada e bastante uniforme.

Os frutos foram transportados ao Laboratório de Fisiologia Pós-Colheita do Departamento de Ciências Biológicas da Escola Superior de Agricultura "Luiz de Queiroz", onde se realizou rigorosa seleção, visando à padronização dos frutos quanto ao tamanho, bem como à eliminação dos frutos de qualidade inferior à desejada.

Foram selecionados 225 frutos e imediatamente acondicionados em bandejas de isopor (144 x $208 \mathrm{~mm})$, totalizando 45 bandejas contendo cinco frutos cada uma.

Os frutos foram então submetidos ao processo de remoção da adstringência mediante a exposição ao vapor 
de álcool etílico hidratado 92,8 INPM (álcool comercial). Para tal foram utilizadas câmaras B.O.D. (Biologic Oxygen Demand, Modelo TE 390-Tecnal) contendo 3,85 mL de álcool/L câmara $\left(3,85 \mathrm{~L} \mathrm{~m}^{-3}\right)$. Durante o processo, a temperatura foi mantida a $20^{\circ} \mathrm{C}$, e a umidade relativa, em torno de $95 \%$. Os frutos permaneceram expostos ao vapor de álcool etílico durante períodos distintos de 24,36 ou 48 horas.

Terminado o período de exposição, os frutos foram retirados das câmaras e colocados em bancadas de laboratório, à temperatura ambiente $\left(24-25^{\circ} \mathrm{C}\right)$.

As características químicas e físicas dos frutos foram avaliadas em intervalos de dois dias, durante o período de dez dias.

As variáveis analisadas foram: a) teor de taninos solúveis (g $100 \mathrm{~g}^{-1}$ polpa): determinado espectrofotometricamente, utilizando-se o reagente de Follin-Denis, segundo técnica recomendada por Carvalho et al. (1990), em que uma amostra de $5 \mathrm{~g}$ de polpa triturada e homogeneizada foi diluída para um volume final de $100 \mathrm{~mL}$ com água destilada, do qual se retirou uma alíquota de $5 \mathrm{~mL}$. A esta alíquota se adicionou reagente de Follin-Denis e solução de carbonato de sódio, completando o volume a $100 \mathrm{~mL}$ com água destilada. Após um período de 30 minutos, a solução foi filtrada, e em seguida determinou-se a absorbância a $760 \mathrm{~nm}$. Foi utilizada, como padrão, uma solução de ácido tânico $\left(0,1 \mathrm{~g} \mathrm{~L}^{-1}\right)$; b) firmeza de polpa $\left(\mathrm{kg} \mathrm{cm}^{-2}\right)$ : medida com penetrômetro EFFE-GI, com ponteira de $6,5 \mathrm{~mm}$ de diâmetro, efetuando-se duas leituras em lados opostos na região equatorial dos frutos, após a remoção de uma pequena área da casca. Associou-se o início do amolecimento da polpa ao valor de firmeza de $5 \mathrm{~kg} \mathrm{~cm}^{-2}$; c) perda de matéria fresca (\%): avaliada durante o período de exposição ao vapor de álcool etílico e calculada pela diferença, em porcentagem, entre a massa inicial, e a obtida imediatamente após o tratamento. Avaliada durante os dez dias após o tratamento, em intervalos de dois dias, considerando-se como massa inicial aquela verificada imediatamente após o tratamento; d) pH: medido por potenciometria em amostra triturada e homogeneizada; e) sólidos solúveis totais $\left({ }^{\circ}\right.$ Brix): determinados por refratometria, com correção de temperatura para $20^{\circ} \mathrm{C}$; f) acidez total titulável (\% ácido málico): determinada por diluição de $10 \mathrm{~mL}$ da amostra em $90 \mathrm{~mL}$ de água destilada, e posterior titulação com solução de $\mathrm{NaOH}$ a $0,1 \mathrm{~N}$, até o $\mathrm{pH}$ de 8,$10 ; \mathrm{g}$ ) teor de ácido ascórbico (mg ácido ascórbico $100 \mathrm{~g}^{-1}$ polpa): determinado segundo metodologia de Carvalho et al. (1990), a qual se baseia na redução do indicador 2,6-diclorobenzenoindofenol (DCFI) pelo ácido ascórbico.

$\mathrm{O}$ delineamento experimental adotado foi inteiramente casualizado, no esquema fatorial $3 \times 5$, sendo três períodos de exposição ao vapor de álcool etílico: 24, 36 e 48 horas, e cinco tempos de avaliação: 2, 4, 6, 8 e 10 dias, perfazendo 15 tratamentos. A cada avaliação foram utilizadas três repetições com cinco frutos por parcela.

Os dados foram submetidos a análise de variância, e as médias referentes à perda de matéria fresca durante o tratamento foram comparadas pelo teste de Tukey a 5\% de probabilidade. Realizou-se regressão polinomial das médias referentes às demais variáveis, obtidas durante o período de dez dias de avaliação.

Uma amostra representativa dos frutos foi submetida a uma avaliação prévia ao tratamento, objetivando a caracterização inicial dos mesmos.

\section{RESULTADOS E DISCUSSÃO}

\section{Taninos solúveis}

Pela análise de regressão, pôde-se observar que houve uma diminuição no teor de taninos solúveis dos frutos durante o tempo de avaliação, linear para os submetidos aos tratamentos de 36 e 48 horas, e quadrática para os frutos submetidos ao período de 24 horas de exposição ao vapor de álcool etílico (Fig. 1).

Observou-se, dois dias após o tratamento, que os frutos expostos ao período de 24 horas apresen-

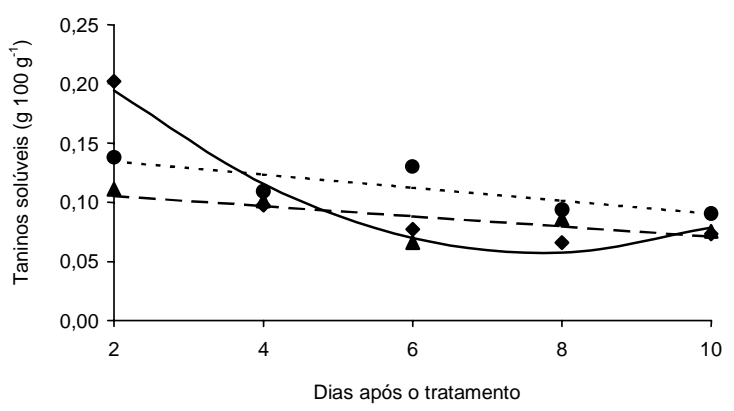

\begin{tabular}{|c|c|c|}
\hline & 24 Horas & \\
\hline$\Delta$ & $\begin{aligned} &-Y=0,3067-0,0644 X+0,0042 X^{2} \\
& 36 \text { Horas }\end{aligned}$ & $R^{2}=0,96^{\star \star}$ \\
\hline-- & $Y=0,1139-0,0043 X$ & $R^{2}=0,55^{\star}$ \\
\hline$\ldots$ & $-Y=0,1456-0,0055 X$ & $R^{2}=0,67^{\star}$ \\
\hline
\end{tabular}

FIG. 1. Teor de taninos solúveis de frutos de caquizeiro 'Giombo', durante o período de 10 dias subseqüentes à exposição ao vapor de

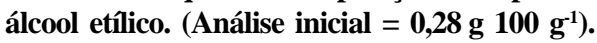
ESALQ, Piracicaba, SP, 1998. 
taram o maior teor de taninos solúveis, equivalente a

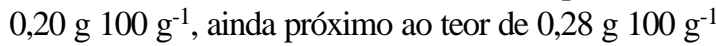
verificado num período imediatamente anterior ao tratamento. Nos demais tempos de avaliação, os teores de taninos solúveis foram próximos nos diferentes períodos de exposição.

De acordo com constatações de Kato (1984b), frutos contendo aproximadamente $0,25 \%$ de tanino revelam-se ligeiramente adstringentes, tornando-se comestíveis quando a concentração de taninos solúveis encontra-se abaixo de $0,1 \%$ (Vidrih et al., 1994). No presente trabalho verificou-se que a partir do quarto dia do tratamento os teores de taninos solúveis foram bastante próximos a $0,1 \%$ em todos os tratamentos, indicando haver uma diminuição da adstringência dos frutos.

Os resultados obtidos estão de acordo com os observados por Fukushima et al. (1991), que relataram a ocorrência de uma leve diminuição da adstringência durante os dois primeiros dias subseqüentes ao tratamento dos frutos com solução de etanol a $35 \%$, que se acentuou nos dois dias seguintes. Kato (1984a), de forma semelhante, verificou a ocorrência de uma "fase lag" de aproximadamente dois dias, à temperatura de $20^{\circ} \mathrm{C}$, antes que tivesse início a diminuição do teor de tanino dos frutos tratados com etanol a $50 \%$.

Biasi \& Gerhardt (1992) obtiveram frutos destanizados próximo ao sexto dia após o tratamento, quando os submeteram à imersão em solução de álcool a 50\%, durante dois minutos. Taira et al. (1992), ao verificarem a existência de frutos adstringentes após seis dias do tratamento com etanol, sugeriram que o teor de taninos solúveis diminui lentamente em função da penetração do etanol através da epiderme do fruto e/ou devido ao metabolismo do álcool a acetaldeído.

\section{Firmeza da polpa}

Pôde-se observar, através da análise de regressão, que houve uma diminuição linear na firmeza da polpa em todos os tratamentos em função do tempo de avaliação (Fig. 2).

Ao final do período de dez dias, os frutos submetidos a 24 horas de exposição ao vapor de álcool etílico apresentaram firmeza de polpa de $5,56 \mathrm{~kg} \mathrm{~cm}^{-2}$,

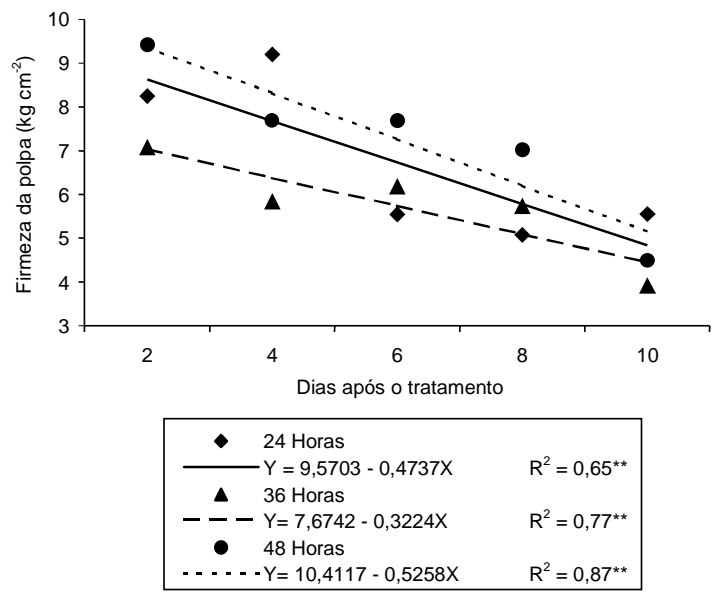

FIG. 2. Firmeza da polpa de frutos de caquizeiro 'Giombo', durante o período de 10 dias subseqüientes à exposição ao vapor de álcool etílico. (Análise inicial $=10,53 \mathrm{~kg} \mathrm{~cm}^{-2}$ ). ESALQ, Piracicaba, SP, 1998.

enquanto os submetidos ao período de 48 horas apresentaram firmeza de $4,49 \mathrm{~kg} \mathrm{~cm}^{-2}$. Os frutos mais amolecidos, submetidos ao tratamento de 36 horas, apresentaram firmeza de polpa de $3,90 \mathrm{~kg} \mathrm{~cm}^{-2}$. Sugere-se que o melhor período para consumo dos frutos se estenda até o oitavo dia após o tratamento, quando se verificou que a firmeza da polpa ainda se manteve aceitável em todos os tratamentos, considerando-se que os frutos desta cultivar são consumidos com polpa firme.

O etileno é considerado um ativador do mecanismo de amolecimento de frutos de caquizeiro (Itamura et al., 1991). Conforme constatações de Itamura et al. (1997), o tratamento com vapor de álcool, bem como outros tratamentos para a remoção da adstringência, acelera a síntese de etileno e, portanto, o amolecimento do fruto.

Frutos tratados com etanol apresentaram um aumento na síntese de etileno cerca de 24 horas após o tratamento (Kato, 1984a; Itamura et al., 1991), enquanto o início do amolecimento da polpa dos frutos ocorreu somente após um período de 48 horas do tratamento (Itamura et al., 1991).

De forma semelhante às observações de Itamura et al. (1991), verificou-se, no presente experimento, uma diminuição na firmeza da polpa dos frutos, dois 
dias após o término do tratamento, passando de $10,53 \mathrm{~kg} \mathrm{~cm}^{-2}$ para $8,24,7,07$ e $9,41 \mathrm{~kg} \mathrm{~cm}^{-2}$, nos períodos de 24, 36 e 48 horas de exposição, respectivamente.

Tian et al. (1991) relataram uma diminuição na atividade da pectinaesterase concomitante à diminuição linear da firmeza da polpa de frutos de caquizeiro durante o período de armazenamento; verificaram, no entanto, um aumento no teor de pectinas solúveis, bem como na atividade da celulase e da poligalacturonase. $\mathrm{O}$ aumento na atividade destas enzimas é responsável pela redução na força de coesão que mantém as células unidas, resultando na diminuição da firmeza da polpa dos frutos (Moura, 1995).

\section{Perda de matéria fresca durante o tratamento}

Os frutos submetidos ao tratamento de 48 horas apresentaram maior perda de matéria fresca durante o período de exposição ao vapor de álcool etílico, seguidos pelos frutos submetidos aos tratamentos de 36 e 24 horas (Fig. 3).

\section{Perda de matéria fresca durante o período de avali- ação}

Pela análise de regressão, pôde-se observar que houve um aumento linear na perda de matéria fresca em razão do tempo de avaliação (Fig. 4), e que não houve efeito do período de exposição sobre esta variável (Tabela 1).

Constatou-se, ao final do período de dez dias, uma perda de matéria fresca equivalente a $5,34 \%$ da massa inicial obtida ao final do tratamento.

A perda de matéria fresca dos frutos ocorre principalmente em face do processo de transpiração, em conseqüência do déficit de pressão de vapor (DPV), que corresponde à diferença entre a pressão de vapor dos espaços intercelulares do fruto e do ar circundante, e do coeficiente de transpiração (CT) do fruto, que corresponde à perda de umidade de um produto em uma unidade de tempo por DPV (Woods, 1990).
Considerando-se que as perdas de matéria fresca entre $3 \%$ e $6 \%$ são suficientes para causar redução na qualidade de muitos produtos vegetais (Chitarra \& Chitarra, 1990), sugere-se que os frutos submetidos a este processo de destanização sejam comercializados tão logo estejam aptos ao consumo, ou seja, a partir do quarto dia após o tratamento, considerando-se o teor de taninos solúveis e a perda de matéria fresca.

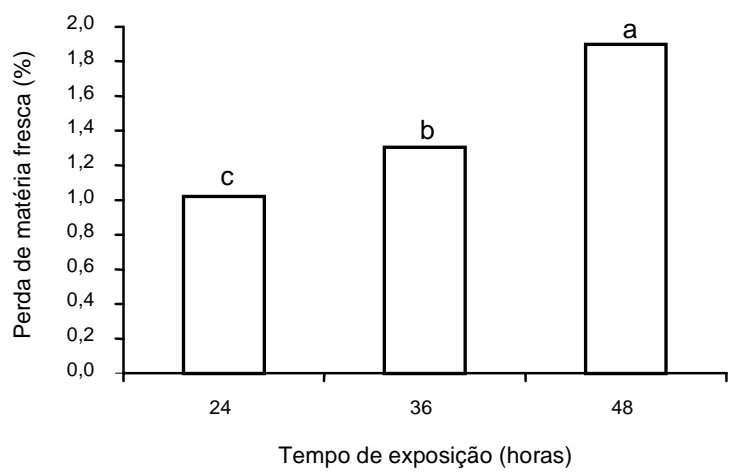

FIG. 3. Perda de matéria fresca de frutos de caquizeiro 'Giombo' durante o período de exposição ao vapor de álcool etílico. (As letras minúsculas indicam diferença significativa ao nível de $5 \%$ de probabilidade, pelo teste de Tukey). ESALQ, Piracicaba, SP, 1998.

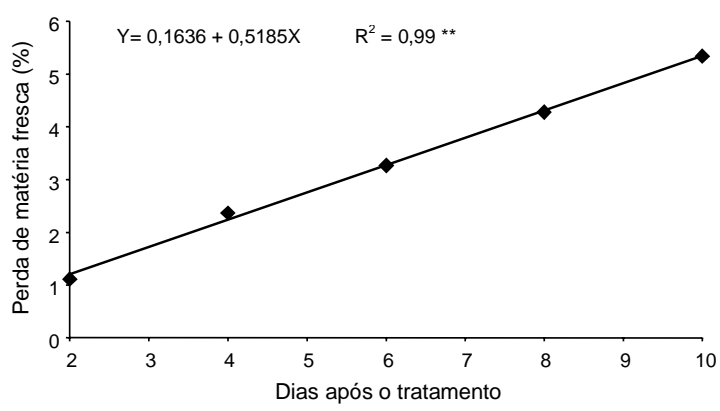

FIG. 4. Perda de matéria fresca de frutos de caquizeiro 'Giombo', durante o período de dez dias subseqüientes à exposição ao vapor de álcool etílico. ESALQ, Piracicaba, SP, 1998. 
TABELA 1. Análise de variância dos efeitos de diferentes períodos de exposição e do tempo de avaliação das variáveis taninos solúveis (TS), firmeza de polpa (FP), perda de matéria fresca durante o tratamento (PMFT), perda de matéria fresca durante o período de avaliação (PMFA), potencial hidrogeniônico (pH), sólidos soluveis totais (SST), acidez total titulável (ATT) e ácido ascórbico (AA), analisadas em frutos de caquizeiro 'Giombo'. ESALQ, Piracicaba, SP, 1998.

\begin{tabular}{lcccccccc}
\hline Fontes de variação & TS & FP & PMFT & PMFA & pH & SST & ATT & AA \\
\hline Período de exposição (PE) & $*$ & $* *$ & $* *$ & ns & ns & ns & ns & \\
Tempo de avaliação (TA) & $* *$ & $* *$ & - & $* *$ & $* *$ & ns & ns & $* *$ \\
PE x TA & $* *$ & $*$ & - & ns & ns & ns & ns & ns \\
C.V. $(\%)$ & 22,15 & 15,72 & 17,33 & 10,92 & 1,10 & 2,50 & 12,26 & 11,32 \\
\hline n.s. ** ${ }^{*}$ Não-significativo e significativo a 1\% e 5\% de probabilidade, respectivamente. & & & &
\end{tabular}

\section{Potencial hidrogeniônico (pH)}

Por meio da análise de regressão, constatou-se que a variação desta característica em função do tempo pôde ser representada através de uma equação quadrática (Fig. 5).

Verificou-se uma redução no valor do $\mathrm{pH}$ no segundo dia após o tratamento, passando de 6,22, no período anterior ao tratamento, para 6,08. Os valores se mantiveram próximos até o sexto dia, verificandose, a partir deste ponto, uma redução no valor de $\mathrm{pH}$, atingindo o valor de 5,85 ao final de dez dias, valor este superior ao de 5,50 encontrado por Costa (1984), em frutos da mesma cultivar submetidos ao tratamento com acetileno.

Estes resultados estão de acordo com os obtidos por Biasi \& Gerhardt (1992), que verificaram uma redução significativa no $\mathrm{pH}$ com o amadurecimento dos frutos, durante o período de oito dias subseqüentes ao tratamento com álcool. Moura (1995) obteve resultados semelhantes ao submeter caquis 'Taubaté' a pulverização com solução de ethephon a $1.000 \mathrm{mg} \mathrm{L}^{-1}$, visando induzi-los ao amadurecimento.

\section{Sólidos solúveis totais}

Observou-se, durante todo o período de avaliação, que os teores de sólidos solúveis mantiveramse muito próximos, apresentando-se, no entanto, superiores à média verificada durante a caracterização inicial dos frutos, equivalente a $20,87^{\circ}$ Brix (Fig. 6).

O aumento do teor de sólidos solúveis verificado em relação ao valor médio inicial pode ser resultado

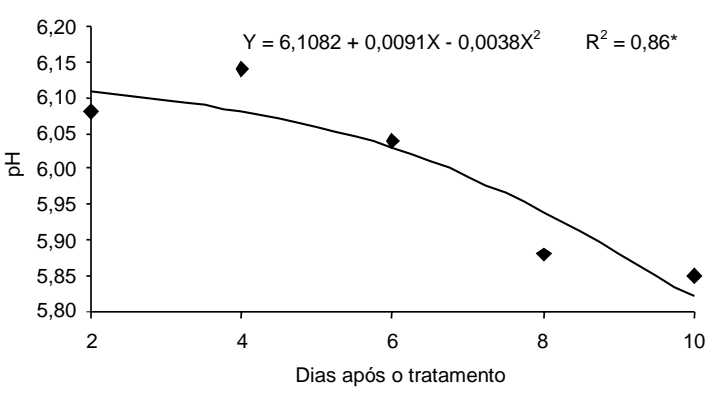

FIG. 5. Potencial hidrogeniônico da polpa de frutos de caquizeiro 'Giombo', durante o período de dez dias subseqüientes à exposição ao vapor de álcool etílico. (Análise inicial = 6,22). ESALQ, Piracicaba, SP, 1998.

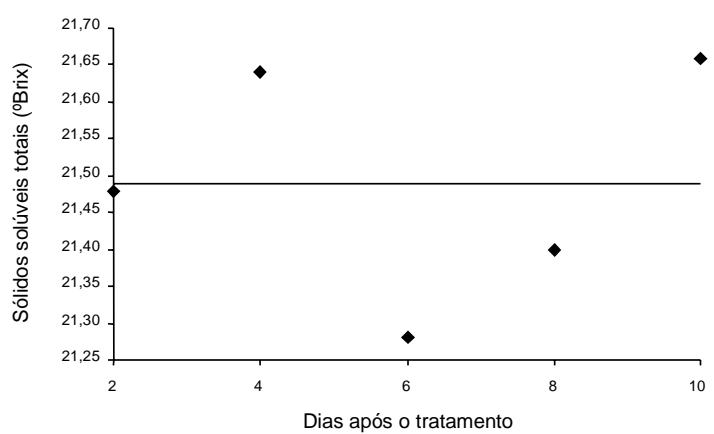

FIG. 6. Teor de sólidos solúveis totais de frutos de caquizeiro 'Giombo', durante o período de dez dias subseqüentes à exposição ao vapor de álcool etílico. (Análise inicial = 20,87 Brix). ESALQ, Piracicaba, SP, 1998.

da perda de matéria fresca pelos frutos durante o período de exposição ao vapor de álcool e da hidrólise 
de compostos, como substâncias pécticas e hemicelulose da parede celular, em conseqüência do avanço do amadurecimento, conforme sugerem Wills et al. (1981).

A ausência de aumento desta característica ao longo do período de avaliação, pode estar relacionada à respiração do fruto, que utilizou os açúcares como substrato para o processo. A perda de matéria fresca verificada nos frutos, que normalmente faz com que o teor de sólidos solúveis totais se eleve, pode ter contrabalançado as perdas dos carboidratos utilizados no processo respiratório, havendo, portanto, pouca variação na característica avaliada.

\section{Acidez total titulável}

Era de se esperar que houvesse aumento na acidez, confirmando o comportamento do $\mathrm{pH}$; no entanto, constatou-se que os valores mantiveram-se muito próximos durante o período de dez dias, não diferindo, inclusive, do valor médio de $0,0625 \%$ de ácido málico, verificado durante o período imediatamente anterior ao tratamento (Fig. 7).

Embora não havendo diferença significativa entre os teores de acidez total titulável nos diferentes tempos de avaliação, verificou-se, ao segundo dia do tratamento, o menor valor médio de acidez, equivalente a $0,0655 \%$ de ácido málico.

O teor de ácidos orgânicos, com poucas exceções, diminui com a maturação, em decorrência do processo respiratório ou de sua conversão em açúcares (Chitarra \& Chitarra, 1990). No entanto, Moura (1995) atribuiu o aumento da acidez verificado em frutos de caquizeiro 'Taubaté' submetidos ao tratamento com ethephon, à intensa atividade metabólica, que conduz às transformações físicas e químicas nos frutos. $\mathrm{O}$ ácido poligalacturônico, proveniente da hidrólise da pectina pela pectinametilesterase e poligalacturonase (Wills et al., 1981), além da produção de intermediários do ciclo de Krebs, como os ácidos orgânicos alfa-ceto glutárico, cítrico e málico, pode contribuir para o aumento da acidez titulável (Moura, 1995).

\section{Ácido ascórbico}

Mediante análise de regressão, constatou-se que a variação desta característica em função do tempo pôde ser representada por uma equação linear (Fig. 8).

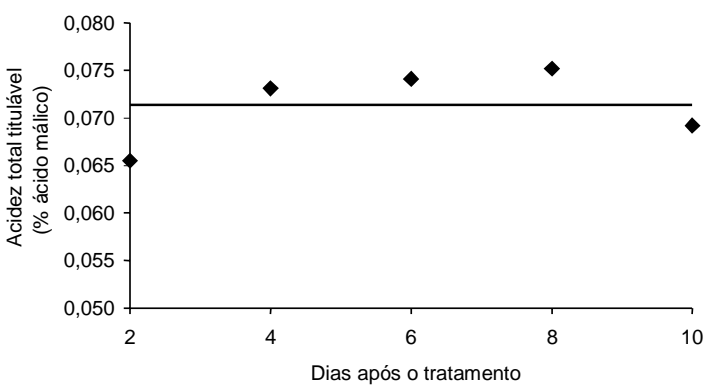

FIG. 7. Acidez total titulável de frutos de caquizeiro 'Giombo', durante o período de dez dias subseqüentes à exposição ao vapor de álcool etílico. (Análise inicial $=\mathbf{0 , 0 6 2 5 \%}$ ácido málico). ESALQ, Piracicaba, SP, 1998.

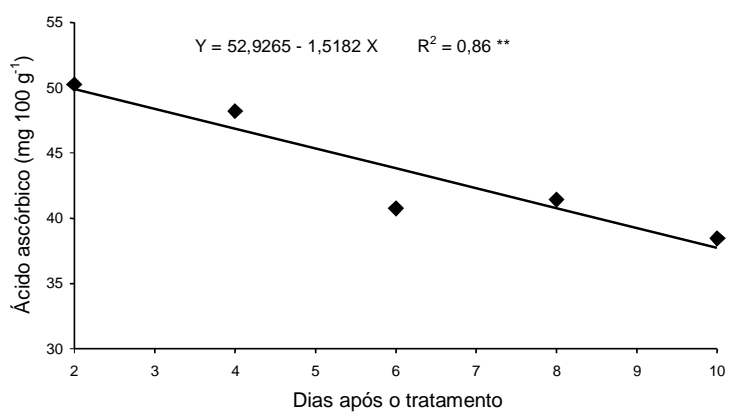

FIG. 8. Teor de ácido ascórbico de frutos de caquizeiro 'Giombo', durante o período de dez dias subseqüentes à exposição ao vapor de álcool etílico. (Análise inicial =

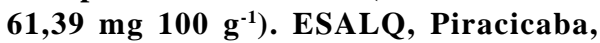
SP, 1998.

Observou-se um decréscimo linear no teor de ácido ascórbico a partir do segundo dia após o tratamento, atingindo o menor teor ao final do período, equivalente a $38,45 \mathrm{mg}$ de ácido ascórbico/ $100 \mathrm{~g}$ de polpa. Considerando-se que o teor médio de ácido ascórbico obtido imediatamente anterior ao tratamen-

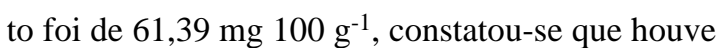
uma perda de vitamina $\mathrm{C}$ equivalente a $37,4 \%$, desde o início do tratamento até o término do período de avaliação.

Tais resultados estão de acordo com os obtidos por Montenegro \& Salibe (1959), que afirmaram que 
o caqui apresenta uma variação no teor de vitamina $\mathrm{C}$ em função do grau de maturação, apresentando, os frutos verdolengos, maior teor em vitamina $\mathrm{C}$ que os frutos maduros ou senescentes. Taira et al. (1987) obtiveram resultados semelhantes, constatando uma ligeira alteração nos teores de ácido ascórbico de frutos de caquizeiro que tiveram sua adstringência removida através do tratamento com álcool em pós-colheita.

Ao contrário dos resultados obtidos, Montenegro \& Salibe (1959) relataram que o tratamento de frutos de caquizeiro 'Coração de Boi' com solução de ácido acético, visando a antecipação da maturação, pareceu evitar a diminuição normal do teor de vitamina $\mathrm{C}$ durante o processo de amadurecimento.

A exposição dos frutos ao vapor de álcool etílico, como um processo de antecipação da maturação, promove uma antecipação da ascensão climatérica, envolvendo um aumento na taxa respiratória (Itamura et al., 1997). Conforme relataram Chitarra \& Chitarra (1990), a respiração resulta em modificações profundas dos constituintes do fruto, dentre os quais encontram-se as vitaminas.

\section{CONCLUSÕES}

1. A exposição de frutos de caquizeiro ao vapor de álcool etílico é um método prático e eficiente no processo de destanização.

2. A remoção da adstringência mediante a exposição de frutos de caquizeiro 'Giombo' ao vapor de álcool etílico pode ser realizada no período de 24 horas.

3. O melhor período para consumo dos frutos situa-se entre o quarto e o oitavo dia após o tratamento.

\section{REFERÊNCIAS}

BIASI, L.A.; GERHARDT, I.R. Efeito da aplicação de vinagre, álcool e ethephon na destanização de caquis cv. Okira. Revista Brasileira de Fruticultura, Cruz das Almas, v.14, n.2, p.31-36, 1992.

BUREN, J. van. Fruit phenolics. In: HULME, A.C. (Ed.). The biochemistry of fruits and their products. London : Academic, 1970. v.1, p.269-304.
CAMPO-DALL'ORTO, F.A.; OJIMA, M.; BARBOSA, W.; ZULLO, M.A.T. Novo processo de avaliação da adstringência dos frutos no melhoramento do caquizeiro. Bragantia, Campinas, v.55, n.2, p.237243, 1996.

CARVALHO, C.R.L.; MANTOVANI, D.M.B.; CARVALHO, P.R.N.; MORAES, R.M.M. Análises químicas de alimentos. Campinas : Instituto de Tecnologia de Alimentos, 1990. 121p. Manual Técnico.

CHITARRA, M.I.F.; CHITARRA, A.B. Pós-colheita de frutos e hortaliças: fisiologia e manuseio. Lavras : ESAL/FAEPE, 1990. 293p.

COSTA, A.N. da. Produção e qualidade dos frutos de diferentes variedades de caqui (Diospyros kaki L.), visando à industrialização. Viçosa : UFV, 1984. 50p. Dissertação de Mestrado.

FUKUSHIMA, T.; KITAMURA, T.; MURAYAMA, H.; YOSHIDA, T. Mechanisms of astringency removal by ethanol treatment in 'Hiratanenashi' kaki fruits. Japanese Society for Horticultural Science Journal, Tokyo, v.60, n.3, p.685-694, 1991.

ITAMURA, H.; KITAMURA, T.; TAIRA, S.; HARADA, H.; ITO, N.; TAKAHASHI, Y.; FUKUSHIMA, T. Relationship between fruit softening, ethylene production and respiration in Japanese persimmon 'Hiratanenashi'. Japanese Society for Horticultural Science Journal, Tokyo, v.60, n.3, p.695-701, 1991.

ITAMURA, H.; OHHO, Y.; YAMAMURA, H. Characteristics of fruit softening in Japanese persimmon 'Saijo'. Acta Horticulturae, Leuven, n.436, p.179-188, 1997.

ITO, S. The persimmon. In: HULME, A.C. (Ed.).The biochemistry of fruits and their products. London : Academic, 1971. v.2, p.281-301.

KATO, K. Astringency removal and ripening as related to ethanol concentration in persimmon fruits. Japanese Society for Horticultural Science Journal, Tokyo, v.53, n.3, p.278-289, 1984a.

KATO, K. Astringency removal and ripening as related to temperature during the astringency removal by ethanol in persimmon fruits. Japanese Society for Horticultural Science Journal, Tokyo, v.55, n.4, p.498-509, 1987. 
KATO, K. Conditions for tanning and sugar extraction, the relationship of tannin concentration to astringency and the behaviour of ethanol during the removal of astringency by ethanol in persimmon fruits. Japanese Society for Horticultural Science Journal, Tokyo, v.53, n.2, p.127-134, 1984b.

MARTINS, F.P.; PEREIRA, F.M. Cultura do caquizeiro. Jaboticabal : FUNEP, 1989. 71p.

MONTENEGRO, H.W.S.; SALIBE, A.A. Vitamina C em caqui (Diospyros kaki L.). Revista de Agricultura, Piracicaba, v.34, n.3, p.183-195, 1959.

MOURA, M.A. da. Efeito da embalagem e do armazenamento no amadurecimento do caqui (Diospyros kaki L.) cultivar Taubaté. Viçosa : UFV, 1995. 84p. Dissertação de Mestrado.

PENTEADO, S.R. Cultura do caquizeiro. In: PENTEADO, S.R. Fruticultura de clima temperado em São Paulo. Campinas : Fundação Cargill, 1986. p.157-173.

PESIS, E.; LEVI, A.; BEN-ARIE, R. Deastringency of persimmon fruits by creating a modified atmosphere in polyethylene bags. Journal of Food Science, Chicago, v.51, n.4, p.1014-1016, 1041, 1986.

SUGIURA, A.; TOMANA, T. Relationships of ethanol production by seeds of different types of Japanese persimmons and their tannin content. HortScience, Alexandria, v.18, n.3, p.319-321, 1983.

TAIRA, S.; KUBO, Y.; SUGIURA, A.; TOMANA, T. Comparative studies of postharvest fruit quality and storage quality in Japanese persimmon (Diospyros kaki L. cv. Hiratanenashi) in relation to different methods for removal of astringency. Japanese Society for Horticultural Science Journal, Tokyo, v.56, n.2, p.215-221, 1987.

TAIRA, S.; SATOH, I.; WATANABE, S. Relationship between differences in the ease of removal of astringency among fruits of Japanese persimmon (Diospyros kaki Thunb.) and their ability to accumulate ethanol and acetaldehyde. Japanese Society for Horticultural Science Journal, Tokyo, v.60, n.4, p.1003-1009, 1992.

TIAN, J.W.; XU, M.X.; HE, P.C. Study on the physiology of postharvest softening of Diospyros kaki fruits. Plant Physiology Communications, Beijing, v.2, p.109-111, 1991.

VIDRIH, R.; SIMCIC, M.; HRIBAR, J.; PLESTENJAK, A. Astringency removal by high $\mathrm{CO}_{2}$ treatment in persimmon fruit (Diospyros kaki). Acta Horticulturae, Leuven, n.368, p.652-656, 1994.

WILLS, R.H.H.; LEE, T.H.; GRAHAM, D.; McGLASSON, W.B.; HALL, E.G. Postharvest: an introduction to the physiology and handling of fruit and vegetables. Kensington : New South Wales University Press, 1981. 161p.

WOODS, J.L. Moisture loss from fruits and vegetables. Postharvest News and Information, Wallingford, v.1, n.3, p.195-199, 1990. 